\title{
The expression of apolipoproteina1 and its correlation with infiltration of urologic neoplasm
}

\author{
Huihui $\mathrm{Hu}^{1}$, Bei Gong ${ }^{1}$, Man Zhang ${ }^{1,2,3}$ \\ ${ }^{1}$ Department of Clinical Laboratory, Beijing Shijitan Hospital, Capital Medical University, Beijing 100038, China; ${ }^{2}$ Beijing Key Laboratory of \\ Urinary Cellular Molecular Diagnostics, Beijing 100038, China; ${ }^{3}$ Clinical Laboratory Medicine, Peking University Ninth School of Clinical \\ Medicine, Beijing 100038, China \\ Contributions: (I) Conception and design: M Zhang; (II) Administrative support: M Zhang; (III) Provision of study materials or patients: H Hu, B \\ Gong; (IV) Collection and assembly of data: H Hu; (V) Data analysis and interpretation: H Hu; (VI) Manuscript writing: All authors; (VII) Final \\ approval of manuscript: All authors. \\ Correspondence to: Prof. Man Zhang, MD. PhD. Chief of Clinical Laboratory Medicine, Beijing Shijitan Hospital, Capital Medical University, \\ Beijing 100038, China; Chief of Beijing Key Laboratory of Urinary Cellular Molecular Diagnostics, Beijing 100038, China; Department of Clinical \\ Laboratory, Beijing Shijitan Hospital, Capital Medical University, 10 Tieyi Road, Haidian District, Beijing 100038, China. \\ Email: zhangman@bjsjth.cn.
}

\begin{abstract}
Background: To explore the differential expression of apolipoproteinA1 (APOA1) in urologic neoplasm patient compared with controls, as well as investigates whether APOA1 correlated with infiltration of urologic neoplasm.
\end{abstract}

Methods: A total of 59 tissue sections of surgically-resected urologic neoplasm and 6 cases of normal tissue sections were collected. Fourteen cases of urine samples from transitional cell carcinoma patients and 6 cases urine samples from controls were also applied in this experiment. We also selected 6 cases of fresh bladder transitional cell carcinoma tissues. The urologic neoplasm tissue sections were classified into infiltration and non-infiltration urologic neoplasm groups. The expressions of APOA1 between urologic neoplasm and normal control were detected by Western blot, Immunohistochemistry and qRT-PCR. The method of Immunohistochemistry was applied to examine the differences of APOA1 expression between infiltration and non-infiltration urologic neoplasm tissue section groups.

Results: Compared with none expression in normal controls, APOA1 was exhibited higher level in urologic neoplasm patient's urine and fresh bladder transitional cell carcinoma tissues $(\mathrm{P}<0.05)$. There were statistical differences of APOA1 between infiltration and non-infiltration urologic neoplasm tissue section groups. APOA1 expressions were found to be up-regulated in the infiltration neoplasm tissue sections compared to non-infiltration group $(\mathrm{P}<0.001)$.

Conclusions: APOA1 could act as a valuable biomarker for predicting the occurrence and development of urologic neoplasm.

Keywords: ApolipoproteinA1 (APOA1); urologic neoplasm; infiltration; tissue sample; urine; immunohistochemistry

Submitted Apr 10, 2019. Accepted for publication Oct 10, 2019.

doi: $10.21037 /$ tcr.2019.11.51

View this article at: http://dx.doi.org/10.21037/tcr.2019.11.51

\section{Introduction}

Urologic neoplasm is ranked the second most common tumor that occurs in the urogenital system, including kidney, bladder, prostate, and testicle (1). Carcinogen exposure and the habit of smoking are considered the main etiological factors of urologic neoplasm (2). According to the previous reports, the most common clinical urologic neoplasms are prostate cancer (PC), renal cell carcinoma 
(RCC), bladder cancer (BC) (3). The 5-year survival rate of RCC ranges from $15 \%$ to $50 \%$, according to the different of tumor stage, treatment, and selection. For BC, the $80 \%$ of the $\mathrm{BC}$ is non-invasive (4). Invasive $\mathrm{BC}$ accounts for about $20 \%$ of the annual incidence of $\mathrm{BC}$, amounting to approximately 15,000 deaths per year in the China (3). The patients at early stage (I or II) are more likely to survive with a 5 -year survival rate of $97 \%$, while the patients at advanced stage (III or IV) the 5 -year survival rate is only $6 \%$, as to the cancer has already invaded to other organs, which makes it quite difficult to therapy (4). The previous studies have reported, almost all of the PCs is non-cutaneous cancer in males (5). The most risk of $\mathrm{PC}$ is environment factors, such as diet, smoking etc. Because of the gradual progression and nonspecific symptoms PC is usually diagnosed at advanced stage (6). So finding a valuable biomarker is becoming vital important for the survival rate of urologic neoplasm.

ApolipoproteinA1 (APOA1) which is a major component of the high-density lipoprotein complex has higher expression in the human serum. It also has the function to activate lecithin-cholesterol-acyltransferase (LCAT) in vivo (7). APOA1 is synthetic mainly in the liver and small intestine. The gene methylation of APOA1 determines the expression of the protein $(8,9)$. APOA1 only expresses a little amount in the liver, small intestine, and pancreas in the human body, so the abnormal expression of APOA1 in human is of great significance for the early diagnosis of tumor (10). According to the reports, APOA1 plays a significant role in the process of fat metabolism in the human body. The ration of APOA1/APOB is now used to judge the lipid metabolism in the diseases of coronary atherosclerosis and stroke (11). A large number of studies have reported APOA1 participates in the PPAR-RXR pathways, which involved in the metabolism of tumor cell. The relationship between APOA1 and human tumor is a hot topic, such as APOA1 was expressed lower in the pancreatic cancer and ovarian cancer tissues compared with normal tissues $(12,13)$. Lei et al. has reported APOA1 expressed higher in the $\mathrm{BC}$ urine than the controls (14).

This study aimed to explore the expression of APOA1 between urologic neoplasm tissues and normal urologic tissues. Furthermore, we wanted to verify APOA1 whether correlated with infiltration of urologic neoplasm. The differential expression of APOA1 was investigated between the infiltrated urologic neoplasm tissue sections and noninfiltrated urologic neoplasm tissue sections by the method of immunohistochemistry. Fifty-nine cases of surgically resected urologic neoplasm tissue sections and 6 cases of normal tissue sections were analyzed. The methods of PCR and Western-blot were applied to explore the differential expressions of APOA1 between 6 cases of fresh urologic neoplasm tissues and normal human bladder tissues. The differential expressions of APOA1betwwen urologic neoplasm patients' urine and normal control urine were investigated by the method of Western-blot. We expected APOA1 could be considered a as the biomarker of the occurrence and development of urologic neoplasm, especially the differential expression of APOA1 was found in the urine samples.

\section{Methods}

\section{Sample characteristics}

This study contained 59 cases of surgically resected urologic neoplasm tissue samples and 6 cases of normal tissues. We also collected 14 cases of urine sample respectively from transitional cell carcinoma patients and 6 cases of urine sample from controls. Furthermore, 6 cases of fresh bladder transitional cell carcinoma tissues were also selected. The 6 cases of normal tissues and 6 cases of normal human urine sample acted as the control groups in this experiment. The tissue samples were selected from Beijing Shijitan Hospital and Hebei Xingtai Hospital from 2010.10 to 2013.10. All the patients underwent initial surgery and without any radiotherapy and chemotherapy before surgery. And the inspection found no history of other malignant tumors, eliminated the abnormal metabolism related diseases. The cancer tissue samples were divided into two groups depending on infiltration (not infiltration, infiltration). The details were listed in Table 1. We extracted the protein from the urine and tissues by the methods of centrifugation $\left(12,000 \mathrm{rpm}, 4{ }^{\circ} \mathrm{C}, 30 \mathrm{~min}\right)$; The urine needed ethanol extraction, ethanol was 4 times more than urine $\left(100 \%\right.$ ethanol, $\left.4{ }^{\circ} \mathrm{C}, 30 \mathrm{~min}\right)$. Before centrifugation, the tissues must be cleavage by protease, $37^{\circ} \mathrm{C}, 30 \mathrm{~min}$. The extraction was ultrasound on the ice (ultrasonic $3 \mathrm{~S}$, stop $6 \mathrm{~S}$ ), $30 \mathrm{~min}$ on the ice, concussion every $10 \mathrm{~min}$. After centrifugation, the protein was collected. The concentration of the protein was quantitative by the Bradford assay, then was preserved at $-70{ }^{\circ} \mathrm{C}$. The method of Western-blot was used to explore the differential expression of APOA1 protein expression in the urine and fresh urologic neoplasm tissues. Loading quantity of protein sample was $30 \mu \mathrm{g}$. Each patient signed the informed consent and this study received approval from the Institutional Review Board for the 
Table 1 Tissue characteristics of urologic neoplasm patients

\begin{tabular}{|c|c|c|c|}
\hline Group & Number (n) & Age (y) & Gender (F/M) \\
\hline Non-infiltration & 14 & $62.7 \pm 9.3$ & $2 / 12$ \\
\hline Infiltration & 45 & $64.4 \pm 6.0$ & $7 / 38$ \\
\hline \multicolumn{4}{|l|}{ Classification } \\
\hline Urethral carcinoma & 7 & $60.6 \pm 7.5$ & $1 / 6$ \\
\hline Mixed tumor* & 1 & 62 & $0 / 1$ \\
\hline Epithelioid angiosarcoma & 1 & 58 & $0 / 1$ \\
\hline Inverted papilloma & 1 & 65 & $0 / 1$ \\
\hline
\end{tabular}

*, epithelial and mesenchymal mixed tumor. Age is presented as mean \pm SD.

Protection of Human Subject.

\section{Immunobistochemistry}

The paraffin-embedded tissue blocks were sectioned in $5 \mathrm{~mm}$ slices. The tissues dewaxed $20 \mathrm{~min}$ by xylene, dehydrated with $100 \%, 100 \%, 95 \%$ and $75 \%$ serial ethyl alcohol. After three rinses using PBS $15 \mathrm{~min}$, endogenous peroxidase (Dingguo, Biotechnology, China) blocked $20 \mathrm{~min}$ at room temperature to deprive endogenous peroxidase activity. After three rinses using PBS $15 \mathrm{~min}$, the slides were preincubated with normal goat serum for $30 \mathrm{~min}$ to reduce nonspecific antibody binding. After antigen retrieval, the samples were incubated with antibody against APOA1 (Thermo Fisher MAI-83002, USA) at a dilution of 1:500 (diluted in PBS buffer); after three rinses using PBS, the samples were incubated in HRP-conjugated secondary antibody (DAKO, USA), $30 \mathrm{~min}$ at $37^{\circ} \mathrm{C}$. Then chromogen DAB solution (DAKO, USA) colored $5 \mathrm{~min}$. Then the sections were counterstained with hematoxylin for $2 \mathrm{~min}$, washed in running water, dehydrated with $75 \%$, $95 \%, 100 \%$, and $100 \%$ serial ethyl alcohol. The slides were cleared with xylene.

\section{Assessment of APOA1 in Immunobistochemistry}

Semi-quantitative immunohistochemical detection was used to determine the APOA1 protein level of tissue samples. Cytoplasm immunoreactivity for the APOA1 was scored by evaluating the percentage of positive $\mathrm{BC}$ cells and the intensity of cancer cells. Both the scores were decided under double-blind conditions by three independent pathologists. The percent of positive cells was scored as "0" $(0 \%), " 1$ " (1-10\%), "2" (11-50\%), "3" (51-80\%), “4” (81-100\%). Intensity was scored as " 0 " (no staining), " 1 " (weakly stained), "2" (moderately stained), and "3"(strongly stained). The scores were then classified as follow: "-" (score 0), "+" (score 1-4), “++" (score 5-8), and “+++"“ (score 9-12). In order to do the statistical analysis, the immunohistochemical scores were grouped into low expression group (“-”, “+”) and high expression group (“++”, “+++”).

\section{Western-blot}

We extracted the protein from the fresh tissues and urine by cracking. The Bradford assay was performed for measuring protein concentration. The protein of $30 \mu \mathrm{g}$ was separated by $10 \%$ SDS-PAGE. Separated proteins in SDS-PAGE were electrotransferred to a PVDF membrane (Bio-Rad, USA). The membrane was blocked in 5\% nonfat dry milk in PBST (1× PBS, $0.05 \%$ Tween-20) at room temperature and incubated with $\mathrm{mAb}$ against APOA1 (Thermo Fisher MAI-83002, USA) at a dilution of 1:1,000, mAb against $\beta$-actin (Santa Cruz, CA) at a dilution of 1:200 overnight at $4{ }^{\circ} \mathrm{C}$. Then the PVDF membrane was incubated in horseradish-peroxidase-conjugated goat anti-mouse $\mathrm{IgG}$ antibody (diluted 1:2,000 in PBST buffer) $90 \mathrm{~min}$ at room temperature. The membrane was washed three times in PBST buffer. Electrophoresis strip was detected by the enhanced HRP-DAB chromomeric kit. The intensities of-Electrophoresis strip was tested by Image J software. The value of APOA1 was normalized with respect to the 

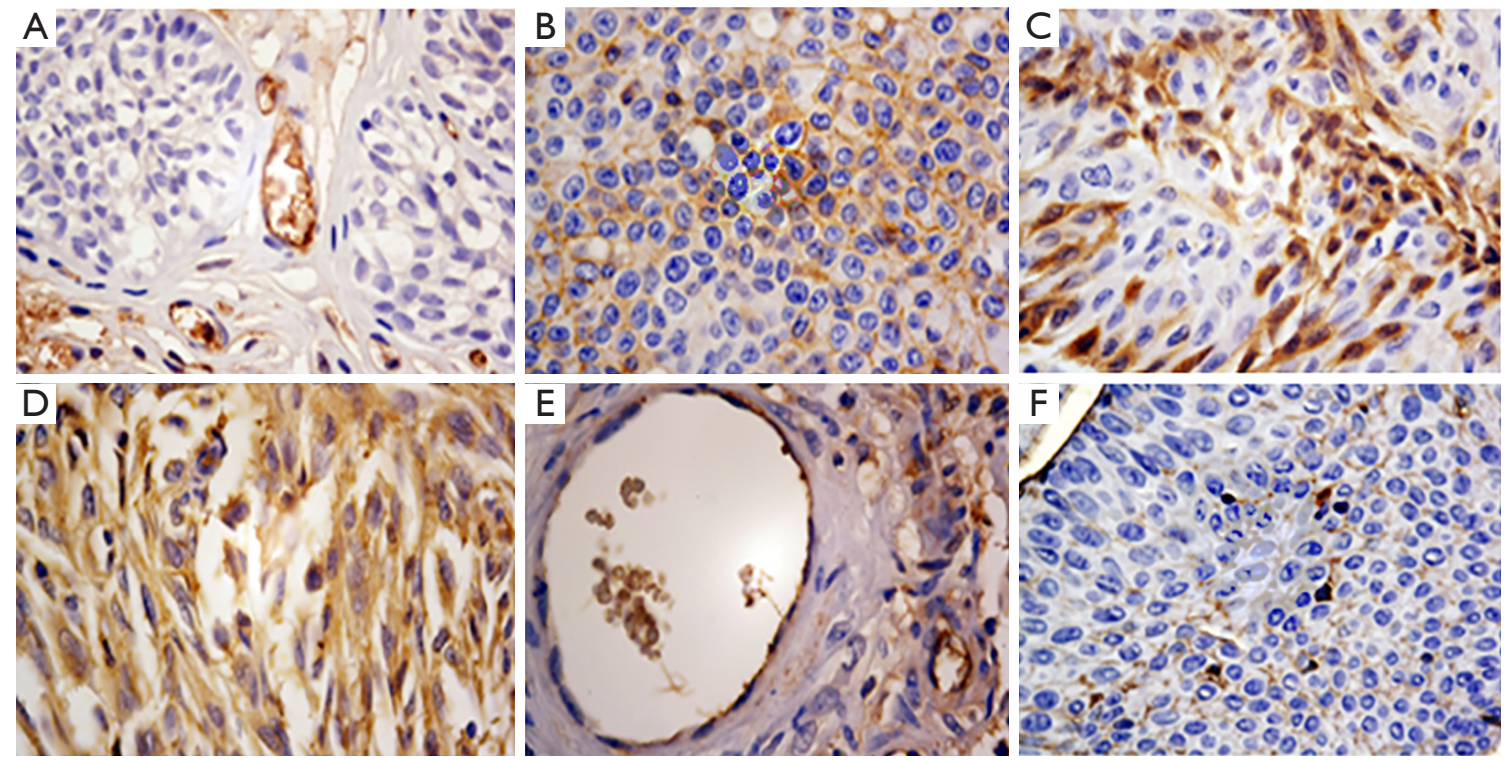

Figure 1 The different location of APOA1 expression in urologic neoplasm tissues. (A) Normal bladder epithelial tissue; (B) bladder cancer tissue; (C) ureteral carcinoma tissue; (D) epithelial and mesenchymal mixed tumor tissue; (E) epithelioid angiosarcoma tissue; (F) inverted papilloma tissue. (HRP, ×400). APOA1, ApolipoproteinA1.

intensities of $\beta$-actin. All of the western blotting analyses were repeated three times.

\section{qRT-PCR}

The RNA from fresh bladder transitional cell carcinoma tissues was extracted using TRIzol reagent (Ambition, life technologies, USA) according to manufacturer's instructions. The RNA weighted $2 \mu \mathrm{g}$ from each sample was obtained to be reverse transcribed and synthesized cDNA. The reaction was performed with oligo $d(T)$ (Dingguo Biotech, China), dNTP (Genview, USA) under the action of M-MLV reverse transcriptase (Promega, USA). qRT-PCR was conducted with Roche Lightcycler 480 Real Time PCR System with TransStart Top Green qPCR SuperMix (TransGen Biotech, China). Primers of APOA1, GAPDH were as follows: APOA1 forward 5'-CGGCAGACTATGTGTCCCA-3', and reverse 5 '-CTGAAGGTGGAGGTCACGCT-3'; GAPDH forward 5'-TTTGGTATCGTGGAAGGACT-3' and reverse 5'-AGTAGAGGCAGGGATGATGT-3'. The program consisted of a pre-incubation step $\left(5 \mathrm{~min}\right.$ at $95^{\circ} \mathrm{C}$, $10 \mathrm{~s}$ at $55^{\circ} \mathrm{C}$, and $10 \mathrm{~s}$ at $\left.72^{\circ} \mathrm{C}\right)$. Then we performed the melting curve step at the condition of $5 \mathrm{~s}$ at $95^{\circ} \mathrm{C}, 1 \mathrm{~min}$ at $65^{\circ} \mathrm{C}$, then melting at $0.11^{\circ} \mathrm{C} / \mathrm{s}$ with continuous acquisition mode until $97^{\circ} \mathrm{C}$. At last, the sample was cooled at $40^{\circ} \mathrm{C}$ for
30 s. 5GAPDH was used as endogenous reference. $2^{-\Delta \Delta \mathrm{Ct}}$ method was applied for evaluated mRNA expression of the target gene. All of the qRT-PCR experiment was repeated three times.

\section{Statistical analysis}

The software of SPSS18.0 was used to do statistical analysis. The differential expressions of APOA1 among each groups were verified by analysis of the Wilcoxon rank and test, Kruskal Wallis rank and Fisher's exact probability method. Two-tailed $\mathrm{P}<0.05$ was accepted as statistically significant difference.

\section{Results}

\section{The location of APOA1 expression in different type of urologic neoplasm tissues by the method of Immunobistochemistry}

APOA1 was located in the membrane and cell plasma of BC and ureteral carcinoma cells. In the epithelial and mesenchymal mixed tumor and epithelioid angiosarcoma, APOA1 was expressed in the cytoplasm. The expression of APOA1 mainly was positioned in the cell membrane of the inverted papilloma. The result is shown in Figure 1. 

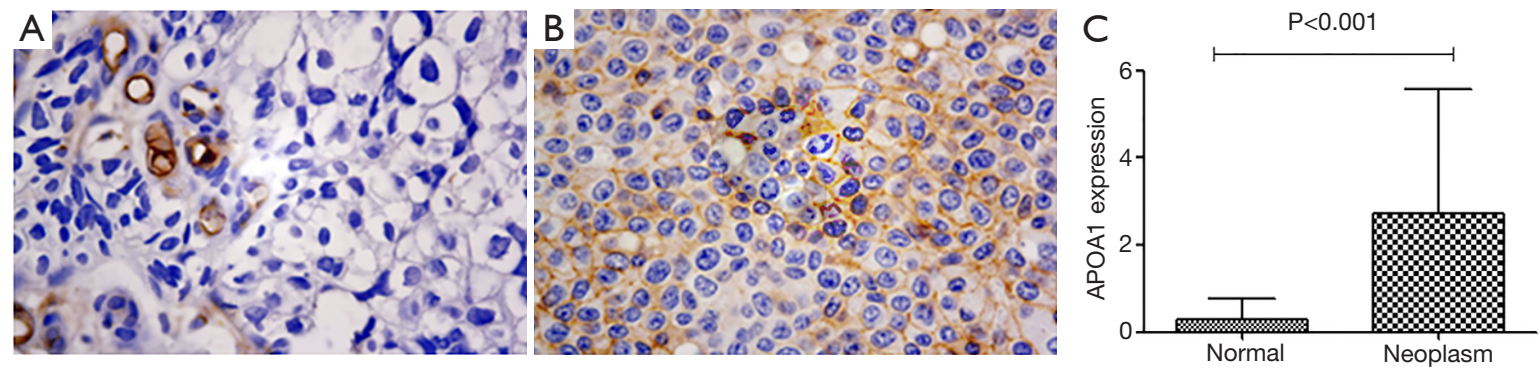

Figure 2 APOA1 expressed higher in the urologic neoplasm tissues compared with normal human tissues by Immunohistochemistry $(\mathrm{P}<0.001)$. (A) Normal human tissues; (B) urologic neoplasm tissues; (C) the statistical analysis between normal group and neoplasm group, the difference had statistical difference. (HRP, ×400). APOA1, ApolipoproteinA1.

A
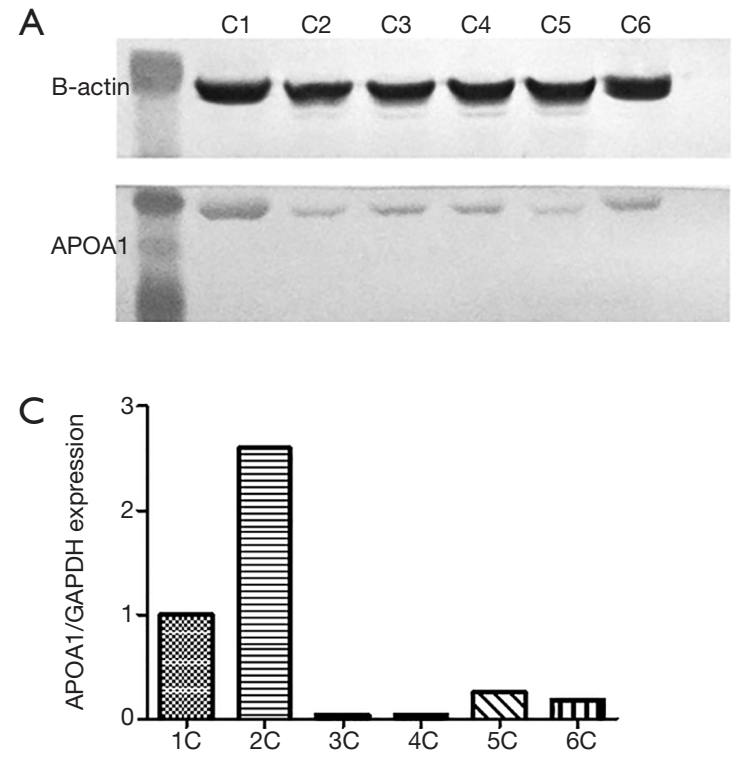

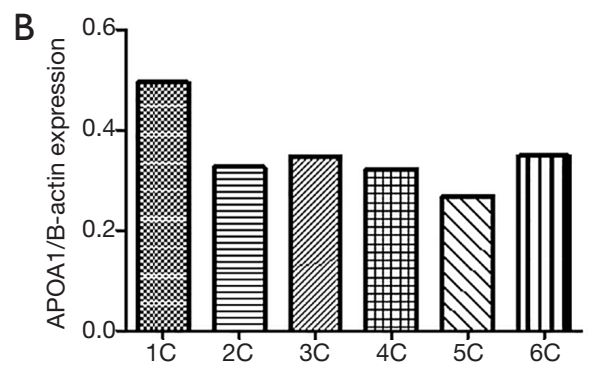

Figure 3 APOA1 expressed significant higher in urologic neoplasm tissues compared with none expression in control group by the method of Western-blot and qRT-PCR. (A) The expression of APOA1 in six cases of urologic neoplasm tissues; (B) the result of APOA1 protein expression in urologic neoplasm tissues by Western-blot; (C) the result of APOA1 RNA expression in urologic neoplasm tissues by qRTPCR. APOA1, ApolipoproteinA1; qRT-PCR, quantitative reverse transcription polymerase chain reaction.

\section{APOA1 expressed higher in urologic neoplasm patient compared to normal buman}

We compared the differential expression of APOA1 between normal human urologic tissues and urologic neoplasm by Immunohistochemistry, Western-blot, and qRT-PCR, APOA1 was expressed higher in the urologic neoplasm than normal human tissues by Immunohistochemistry $(\mathrm{P}<0.001)$. In 53 cases of urologic neoplasm tissues, the positive expression of APOA1 is $81.1 \%$; while in the normal control group, the rate is $28.6 \%$ (Figure 2). While in the fresh urologic neoplasm tissues, APOA1 exhibited higher level compared with normal tissues by the method of Western-blot and qRT-PCR (Figure 3). Compared with none expression of APOA1 in normal human urine, higher expression of APOA1 is found in urologic neoplasm patient's urine (Figure 4).

APOA1 expression in urologic neoplasm tissues is associated with the invasion by Immunohistochemistry

Results showed, higher expression of APOA1 presents in $81.8 \%$ of non-invasive urologic neoplasm tissues (14 
A
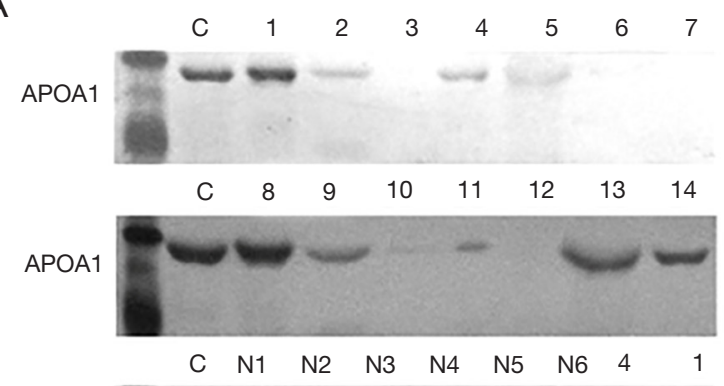

APOA1

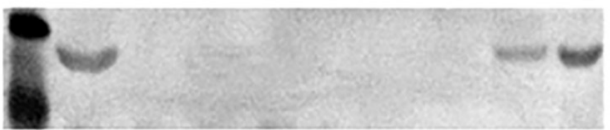

B

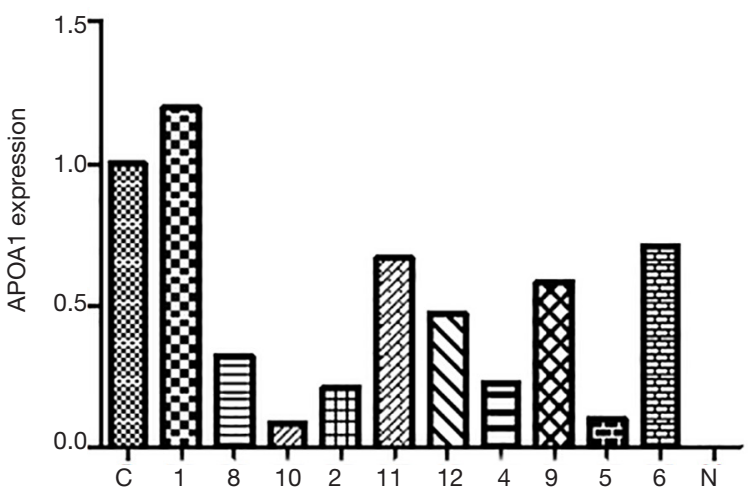

Figure 4 APOA1 expressed higher in urologic neoplasm patient's urine compared with normal control urine. In the Figure $4 A$, C represents the control electrophoresis strip. (A) N1-N6 represents six cases of normal control urine. 1-14 represent 14 cases of urologic neoplasm patients' urine samples. (B) The result of APOA1 protein expression in urologic neoplasm urine by Westernblot. APOA1, ApolipoproteinA1.

cases), while in the 45 cases of invasive neoplasm tissues; the positive rate is $92.3 \%$. APOA1 was noticeably higher in invasive urologic neoplasm tissues than non-invasive, the differences had statistical significant $(\mathrm{P}<0.001$; Figure 5).

\section{Discussion}

Reports showAPOA1 is the main component of plasma high density lipoprotein (HDL) which is constituted by phospholipids, cholesterol, and other lipoprotein and plasma factors. APOA 1 accounts for $70 \%$ of HDL protein content (7). APOA1-mediates the important physiological function in human body, including resistance to atherosclerosis, anti-inflammatory, anti-oxidation, antiendotoxin, combined with vascular walls ATP transporter A-I (ABCA-I), and so on. APOA1 is mainly synthesized in the liver and small intestine. The status of APOA1 gene methylation determines the high tissue specificity of protein expression. The methylation of APOA1 is merely found in the liver, small intestine, pancreas and vascular intima (15). All above indicate APOA1-plays a diverse role in the human body.

In the recent studies, APOA1 correlated with the occurrence and development of tumors in human body had become a hot topic. Li et al. found the APOA1 had higher expression in BC patients' urine by the method of 2-DE and MS, which was confirmed by Western blot and ELISA results. They also showed the expression of Apo-A1 in the urine could be used as a biomarker to diagnosis $\mathrm{BC}$ with a sensitivity and specificity of $89.2 \%$ and $84.6 \%$ (16). Steel et al. had reported, in the proteomics study, the expression of APOA1 significantly decreased in the hepatic cancer patient's serum (17). Gillard et al. verified the APOA1 was expressed little in the HpG2 cell, and the secretion of APOA1 also correlated with the lipid status of the HpG2 cell (18). The expression of APOA1 was also found to have differences between breast cancer patient and controls. Huang compared the differential expressions of APOA1 in plasma protein between breast cancer patient and controls by the method of 2D-DIGE and MS. APOA1 was expressed less in breast cancer patient plasma (19). However, the relationship between APOA1 and urologic neoplasm had been rarely reported.

In the studies of our laboratory, Jin et al. used the method of two-dimensional electrophoresis technology to investigate the differential protein expressions in BC cell line (20). In 2006, it had established the protein map of different stages of bladder transitional cell carcinoma tissues. Zhao had established a map of the different proteins in the urine of PC patients (21). In the urine between BC patients and controls, Ting Lei had reported APOA1 was significantly expressed higher in BC patients' urine (15). Our study focused on the relationship between APOA1 expression and urologic neoplasm, as well as investigated whether APOA1 correlated with infiltration of urologic neoplasm. Guo had studied APOA1 was related with the better survival in patients with surgical RCC (22).

In the present study, APOA1 was expressed higher in urologic neoplasm tissues and urine compared with normal control group. The results demonstrated that APOA1 was up-regulated in urologic neoplasm patient compared with 

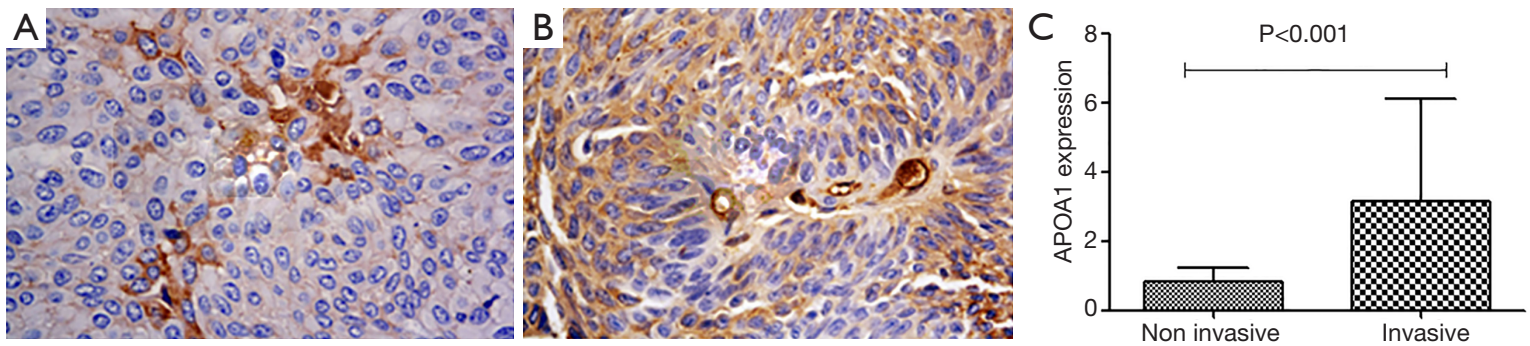

Figure 5 APOA1 was noticeably higher in invasive urologic neoplasm tissues than non-invasive $(\mathrm{P}<0.001)$. (A) Non-invasive urologic neoplasm tissues; (B) invasive urologic neoplasm tissues; (C) the statistical analysis between invasive neoplasm group and non-invasive neoplasm group, the difference had statistical difference. (HRP, ×400). APOA1, ApolipoproteinA1.

normal control people. Especially in the urine sample, APOA1 was found to have expression in urologic neoplasm patient, while had no expression in controls. Considering the urine had the advantage of noninvasive and enrichment, APOA1 might function as a potential molecular marker in the occurrence and development of urologic neoplasm. In conclusion, APOA1 could be considered as a valuable biomarker for the clinicians and patients. APOA1 could afford clinical aid for the diagnosis and therapy of urologic neoplasm. The mechanism between APOA1 and the occurrence and development of urologic neoplasm needed further investigation.

\section{Acknowledgments}

All the authors would like to thank all the staffs in clinical laboratory of Beijing Shijitan Hospital for enthusiastic assistance.

Funding: The project has received funding from Beijing Natural Science Foundation (7172106); Beijing Municipal Administration of Hospital' Ascent Plan, Code: DFL20150701. Enhancement Funding of Beijing Key Laboratory of Urinary Cellular Molecular Diagnostics, Code: 2019-JS02.

\section{Footnote}

Conflicts of Interest: The authors have completed the ICMJE uniform disclosure form (available at http://dx.doi. org/10.21037/tcr.2019.11.51). The authors have no conflicts of interest to declare.

Ethical Statement: The authors are accountable for all aspects of the work in ensuring that questions related to the accuracy or integrity of any part of the work are appropriately investigated and resolved. The study was conducted in accordance with the Declaration of Helsinki (as revised in 2013). This study had gained approval from the Institutional Review Board for the Protection of Human Subjects. The study protocol was approved by the Institutional Review Board of Beijing Shijitan Hospital (No. 2017-q17), and all of the participants signed an informed consent form.

Open Access Statement: This is an Open Access article distributed in accordance with the Creative Commons Attribution-NonCommercial-NoDerivs 4.0 International License (CC BY-NC-ND 4.0), which permits the noncommercial replication and distribution of the article with the strict proviso that no changes or edits are made and the original work is properly cited (including links to both the formal publication through the relevant DOI and the license). See: https://creativecommons.org/licenses/by-nc$\mathrm{nd} / 4.0 /$.

\section{References}

1. Siegel R, Ward E, Brawley O, Jemal A. Cancer statistics: the impact of eliminating socioeconomic and racial disparities on premature cancer deaths. CA Cancer J Clin 2011;61:212-36.

2. Chow TF, Youssef YM, Lianidou E, et al. Differential expression profiling of microRNAs and their potential involvement in renal cell carcinoma pathogenesis. Clin Biochem 2010;43:150-8.

3. Yi Z, Fu Y, Zhao S, et al. Differential expression of miRNA patterns in renal cell carcinoma and nontumorous tissues. J Cancer Res Clin Oncol 2010;136:855-62.

4. Rolf O, Gohlke F. Endoprosthetic elbow replacement in patients with solitary metastasis resulting from renal cell 
carcinoma. J Shoulder Elbow Surg 2004;13:656-63.

5. van der Horst G, Bos L, van der Pluijm G. Epithelial plasticity, cancer stem cells, and the tumor-supportive stroma in bladder carcinoma. Mol Cancer Res 2012;10:995-1009.

6. Wilson M, Merkur H. Hematuria at laparoscopic hysterectomy: a 9-year review at Sydney West Advanced Pelvic Surgery, Australia. J Minim Invasive Gynecol 2008;15:146-51.

7. Huang R, Silva RA, Jerome WG, et al. Apolipoprotein A-I structural organization in high-density lipoproteins isolated from human plasma. Nat Struct Mol Biol 2011;18:416-22.

8. Breslow JL, Ross D, McPherson J, et al. Isolation and characterization of cDNA clones for human apolipoprotein A-I. Proc Natl Acad Sci U S A 1982;79:6861-5.

9. Zhou $\mathrm{L}, \mathrm{He} \mathrm{M}, \mathrm{Wu} \mathrm{C}$, et al. A genome wide association study identifies common variants associated with lipid levels in the Chinese population. PloS One 2013;8:e82420.

10. Sabino AP, De Olivera Sousa M, et al. ApoB/APOA1 ratio in young patients with ischemic cerebral stroke or peripheral arterial disease. Transl Res 2008;152:113-8.

11. Duvillard L, Florentin E, Pont F, et al. Chronic hyperinsulinemia does not increase the production rate of high-density lipoprotein apolipoproteinA1: evidence from a kinetic study in patients with insulinoma. Arterioscler Thromb Vasc Biol 2013;33:2460-5.

12. Zhang Z, Bast RC Jr, Yu Y, et al. Three biomarkers identified from serum proteomic analysis for the detection of early stage ovarian cancer. Cancer Res 2004;64:5882-90.

13. Kozak KR, Su F, Whitelegge JP, et al. Characterization of serum biomarkers for detection of early stage ovarian cancer. Proteomics 2005;5:4589-96.

14. Lei T, Zhao X, Meng Q, et al. Discovery of potential

Cite this article as: $\mathrm{Hu} \mathrm{H}$, Gong B, Zhang M. The expression of apolipoproteinal and its correlation with infiltration of urologic neoplasm. Transl Cancer Res 2020;9(2):690-697. doi: 10.21037/tcr.2019.11.51 bladder cancer biomarkers by comparative urine proteomics and analysis. Clin Genitourin Cancer 2013;11:56-62.

15. Nagae G, Isagawa $T$, Shiraki $\mathrm{N}$, et al. Tissue-specific demethylation in CpG-poor promoters during cellular differentiation. Hum Mol Genet 2011;20:2710-21.

16. Li C, Li H, Zhang T, et al. Discovery of APOA1 as a potential bladder cancer biomarker by urine proteomics and analysis. Biochem Biophys Res Commun 2014;446:1047-52.

17. Steel LF, Shumpert D, Trotter M, et al. A strategy for the comparative analysis of serum proteomes for the discovery of biomarkers for hepatocellular carcinoma. Proteomics 2003;3:601-9.

18. Gillard BK, Lin HY, Massey JB, et al. Apolipoproteins A-I, A-II and E are independently distributed among intracellular and newly secreted HDL of human hepatoma cells. Biochim Biophys Acta 2009;1791:1125-32.

19. Huang HL, Stasyk T, Morandell S, et al. Biomarker discovery in breast cancer serum using 2-D differential gel electrophoresis/MALDI- TOF/TOF and data validation by routine clinical assays. Electrophoresis 2006;27:1641-50.

20. Jin S, Zhang M, Zhang X, et al. Bidirectional electrophoresis in screening of specific marker proteins for bladder cancer. Journal of Chinese Inspection Medicine 2006;29:445-8.

21. Zhao X, Tian Y, Jin S, et al. The analysis of the proteomic analysis of the prostate hyperplasia. Journal of Capital Medical University 2009;30:277-81.

22. Guo S, He X, Chen Q, et al. The Effect of Preoperative Apolipoprotein A-I on the Prognosis of Surgical Renal Cell Carcinoma. Medicine 2016;95:e3147-57. 